This is the author's Post-print version (final draft post-refereeing as accepted for publication by the journal). The definitive, peer-reviewed and edited version of this article is published as: Feijten P.M. and van Ham M. (2009) Neighbourhood change... reason to leave? Urban Studies 46, $2103-2122$.

http://dx.doi.org/10.1177/0042098009339430

\title{
Neighbourhood change... reason to leave?
}

\section{Peteke Feijten* and Maarten van Ham**}

University of St Andrews, School of Geography \& Geosciences, Irvine Building, North Street, St Andrews, Fife, KY16 9AL, UK. Phone +44 (0)1334 463912, Fax +44 (0)1334 463949, E-mail: *peteke.feijten@st-andrews.ac.uk, **maarten.vanham@st-andrews.ac.uk

\begin{abstract}
Very little attention has been paid to date to the role of a changing neighbourhood as a factor influencing the residential choice process. Especially the social structure of a neighbourhood can change fast as some neighbourhoods experience very high levels of population turnover. Processes of neighbourhood change are often beyond residents' sphere of influence and if a changing neighbourhood causes residential stress, the only way to improve one's neighbourhood is to move to a better one. This study aims to get more insight in the effect of neighbourhood change on residential stress by studying residents' wish to leave their neighbourhood. Using data from the 2002 Housing Demand Survey enriched with neighbourhood characteristics and multilevel logistic regression, we model whether or not people have the wish to leave their neighbourhood. The results show no effect of a change in the socio-economic status of the neighbourhood on moving wishes. A high level of population turnover and an increase of the proportion of non-western ethnic minorities in the neighbourhood increase the probability that residents want to leave their neighbourhood. The latter effect disappears when controlled for residents' subjective opinion about neighbourhood change.
\end{abstract}

Keywords: change, mobility, neighbourhood, residential, segregation, moving wish, population mix, multilevel model

\section{Introduction}

Residential mobility is often conceptualized as a response to residential stress caused by a mismatch between a household's residential needs and preferences and characteristics of its current housing situation (see Wolpert, 1966; Speare, 1974; Speare et al., 1975; Brown \& Moore, 1970; Huff \& Clark, 1978; Lu, 1999). Most of the residential mobility literature focuses on residential stress caused by demographic changes in the household that lead to the need for more (or less) space (Lee et al., 1994; Clark \& Dieleman, 1996). Despite some early consideration of the role of neighbourhood characteristics in understanding residential mobility (see Rossi, 1955; 1980; Huff \& Clark, 1978; Clark \& Onaka, 1983), there is relatively little empirical work explicitly taking the effect of the neighbourhood into account. Recent attention for urban neighbourhoods by policy makers (Parkes et al., 2002) caused a renewed interest in the role of the neighbourhood in understanding mobility (see Parks \& Kearns, 2003; Clark et al., 2004; Permentier et al., 2007; Van Ham \& Feijten, 2008; Van Ham \& Clark, forthcoming). 
It has been argued that neighbourhood change (Sabagh et al., 1969; Boehm \& Ihlanfeldt 1986; Lee et al., 1994) or expectations about future change (Taub et al., 1984) are important factors in understanding residential mobility. People select themselves into a neighbourhood based on the choice for a certain dwelling and known neighbourhood characteristics or expectations about the neighbourhood. When a neighbourhood changes to such an extent that the actual characteristics of the neighbourhood do no longer correspond with the preferred characteristics this can give rise to residential stress (Lee et al., 1994). With on average one in ten people moving every year, neighbourhoods can change very fast in terms of socio-economic composition, family type composition, and ethnic/racial composition (Shevsky \& Bell, 1955; Cybriwsky, 1978). There is evidence that when changes in the ethnic composition of neighbourhoods reach certain 'tipping points' this has an effect on (whites') mobility decisions (Wolf, 1957, 1963; Mayer, 1960; Rapkin \& Grigsby, 1960; Taub et al., 1984; Clark 1991, 1992; Gould Ellen (2000). Apart from the tipping point literature we found only one paper which explicitly studies the effect of neighbourhood change on residential mobility. Lee and colleagues (1994) used a small sample of 484 respondents from Nashville, Tennessee, and modelled 'mobility thoughts' and actual moving behaviour. They found limited and partly counterintuitive empirical evidence that neighbourhood change indicators have an effect on the residential mobility process.

In this study we aim to gain more insight in the effect of neighbourhood change on residential stress. We follow in the footsteps of Lee and colleagues (1994), but are able to use a much larger geocoded dataset for the Netherlands. Although most residential mobility studies analyse realised moving behaviour (some exceptions are Morris et al., 1976; Galster, 1987; Varady 1989; Kearns \& Parkes, 2003) we explicitly study people's wish to leave their neighbourhood. Moving wishes are a direct response to residential stress without people taking into account their resources and restrictions or opportunities or constraints on the local housing market. Moving intentions and plans are often expressed by people who see a possibility to move. Actual mobility behaviour only occurs when there are no restrictions or constraints preventing a wish from being realized (Lu, 1999; Mulder \& Hooimeijer, 1999). De Groot and colleagues (2007) have shown for the Netherlands that one third of those who express an intention to move actually move in the two years after the interview (although it can be expected a higher percentage moves over a longer period). Those least likely to realise a desired move were found to be people facing (financial) restrictions: people belonging to ethnic minority groups, singles, non-employed and people with a low level of education (De Groot et al., 2007).

As we are interested in the effect of neighbourhood change on residential stress, studying actual moving behaviour would bias our outcomes. Studies of actual moving behaviour miss all those people who have the wish to move, but are unable to move because of housing market constraints and the direct and indirect monetary and non-monetary costs involved in moving. Some groups are more successful in realising their wishes than others. In our data (see later for more detail) we found that lower income groups significantly more often state a wish to leave their neighbourhood and more often state that their neighbourhood deteriorated than higher income groups. At the same time, these groups can be expected to be the least likely to realise the wish to leave the neighbourhood. Although not all experiencing residential stress from neighbourhood change have the possibility to move, they might be able to move in the future when individual, economic or housing market circumstances change. Looking at moving wishes gives insight in the mechanisms behind actual moving behaviour, revealing potential consequences of moving behaviour for future patterns of neighbourhood change and segregation. Using data from the 2002 Netherlands Housing Demand Survey, enriched with neighbourhood characteristics, this study reports the effects of several indicators of neighbourhood change on people's wish to leave their 
neighbourhood in the Netherlands. It was hypothesised that those who live in neighbourhoods with a decrease in socio-economic status, an increase in the percentage of non-western ethnic minorities and a high population turnover are more likely to have a wish to leave their neighbourhood.

\section{Theory and literature review}

The literature on mobility decision making provides several theoretical models of moving wishes or mobility thoughts (see for example models by Morris and colleagues, 1976, page 312; Galster, 1987, page 14; Lee and colleagues, 1994, page 254). Moving wishes are generally conceptualised as a first step in the residential mobility process, followed for some people by moving intentions, plans and actual mobility behaviour. The basic idea underlying all models of mobility decision making is that moving wishes are a response to residential stress (Speare et al., 1975; see also Huff \& Clark, 1978). In this section we will review literature on the determinants of moving wishes. Although we are explicitly interested in the wish to leave the neighbourhood, it can be expected that there is an overlap with determinants of the wish to move in general. In some sections we also use literature on the determinants of moving intentions and actual moving behaviour.

All theoretical models of moving wishes include individual and household characteristics and characteristics of the current dwelling or dwelling satisfaction as determinants (see Galster 1987, page 148 for an overview of determinants of mobility plans). Some models also include neighbourhood characteristics or expectations about future neighbourhood change (see Gould Ellen, 2000 on the 'neighbourhood projection hypothesis'). Only the theoretical model by Lee and colleagues (1994) explicitly includes both current neighbourhood characteristics and neighbourhood change variables. Lee and colleagues argued that especially the temporal dimension of neighbourhoods neighbourhood change - is important in understanding moving wishes. Changes in the residential context are important in mobility decision models insofar as they are perceived, evaluated and experienced by residents (Lee et al., 1994). If a neighbourhood changes (objective change or perceived change), this can lead to residential stress when the neighbourhood's characteristics do no longer meet the residents' preferences or needs and objectives (see Bonaiuto et al., 1999; 2003 on 'functional attachment'). Neighbourhood change can have a direct effect on peoples' wish to leave the neighbourhood, but there might be a time lag between neighbourhood change and the development of a moving wish. Changes from one year to the next might be subtle, and only when change accumulates over several years might this lead to the wish to leave.

Based on a literature review we have selected three aspects of neighbourhood change that are most likely to have an influence on the wish to leave the neighbourhood. We will subsequently discuss the effect of a change in socio-economic status of the neighbourhood population, a change in the ethnic composition of a neighbourhood population and a high population turnover in a neighbourhood. At the end of the literature review we will discuss some known factors influencing moving wishes, including static neighbourhood characteristics, for which we will control in our models.

\section{Change in socio-economic status}

A literature review by Harris (1999) suggests that residents' wish to leave their neighbourhood is steered by an attempt to avoid social problems and more specifically, neighbours with low social status. His literature review shows that people are adverse of neighbours who deviate from mainstream norms and values, and they consider low income, 
unemployment and low levels of education as indicators of such deviance (Auletta, 1982; Wilson, 1987; Katz, 1989; Jencks, 1992). It has been found that socially disapproved phenomena such as crime, unemployment and births outside marriage are indeed more common in neighbourhoods where many residents have a low socio-economic status. Especially families with children are concerned that crime and violence are contagious, and therefore carefully select neighbourhoods to protect their families from the "the wrong crowd" (Harris, 1999). Michelson (1977) also found great social status awareness in neighbourhood choice. He asked people who were about to move to a different neighbourhood, to compare themselves to their current and their new neighbours in socioeconomic terms. Most of them characterised themselves as belonging to a higher socioeconomic class than their current neighbours, and to a similar or a somewhat lower class than their new neighbours.

Neighbourhoods with a low socio-economic status can be expected to be far from static. Selective mobility into and out of a neighbourhood can cause the neighbourhood to decline further. According to Skogan (1990) physical disorder plays a very important role in social neighbourhood decline. As a neighbourhood physically deteriorates - evidenced by buildings falling in a state of disrepair, garbage on the streets, and graffiti on walls - some of the better-off residents might become dissatisfied with their living environment and develop a wish to leave their neighbourhood. Those who succeed in leaving are most likely replaced by less affluent families, bringing poverty, unemployment and associated problems to the neighbourhood. And as a result the socio-economic status and the desirability of the neighbourhood drop further. Such a drop might be perceived as a sign that the worst is still to come, which leads to the hypothesis that people are more likely to have the wish to leave their neighbourhood when the socio-economic status of their neighbourhood drops (hypothesis 1).

\section{Change in ethnic composition}

According to Gould Ellen (2000) households tend to associate a growing ethnic minority presence in a neighbourhood with structural decline. This can lead to residential stress resulting in the wish to leave the neighbourhood. The underlying mechanism might be discrimination (Bobo \& Zubrinsky, 1996). Literature on the white flight hypothesis (Crowder, 2000) gives evidence that the likelihood that whites leave their neighbourhood increases with the share of ethnic minorities in the neighbourhood. More support for the idea that recent changes in the ethnic composition of neighbourhoods has an effect on whites' mobility decisions comes from several studies of neighbourhood transitions (Wolf, 1957, 1963; Mayer, 1960; Rapkin \& Grigsby, 1960; Taub et al., 1984).

But there is also literature which casts doubt on the role of (a change in the) ethnic composition of neighbourhoods in understanding mobility (Molotch, 1969; Harris, 1999; Crowder, 2000). This literature focuses on the 'racial proxy hypothesis' (Taub et al., 1984; Clark, 1992; Harris, 1999). The racial proxy hypothesis argues that a whole range of social problems are concentrated in neighbourhoods with a high percentage of ethnic minorities. This is partly because some ethnic minority groups are more likely to be unemployed and poor, and partly because ethnic minorities often end up in poor, deprived and unstable neighbourhoods as a result of limited choice on the housing market. According to the racial proxy hypothesis, people develop the wish to escape ethnic concentration neighbourhoods not because they have an aversion to living near minority group members per se, but because these neighbourhoods are deprived (Crowder, 2000).

Following the racial proxy hypothesis, Harris (1999) claims that if models properly control for ethnic composition and socio-economic composition, moving wishes should not be affected by ethnic composition. It is therefore very important that neighbourhood ethnic 
composition and non-ethnicity neighbourhood characteristics are analysed together (Harris, 1999). On the basis of the above, it was hypothesised that people are more likely to have the wish to leave the neighbourhood when there is an increase of non-western ethnic minorities in the neighbourhood (hypothesis 2). This effect might however disappear once controlled for a change in the socio-economic position of the neighbourhood.

\section{Population turnover}

On average, in the Netherlands, one in ten people move every year. In the larger cities, one in six people move each year. There is large variation in population turnover between neighbourhoods, varying from almost zero to more than 30 percent (turnover defined as the percentage of the neighbourhood population moving within or out of a neighbourhood). In extreme situations, such as urban renewal neighbourhoods, population mobility can be even higher, causing a neighbourhood to change (mostly improve) very fast (Van Beckhoven, 2006). Urban renewal can therefore be expected to have a negative effect on residents' wish to leave their neighbourhood.

According to Andersson \& Bråmå (2004) high neighbourhood population turnover is both a testimony of the low attractiveness of a neighbourhood as well as a contributing cause in the process of neighbourhood decline (See also Bailey \& Livingston, 2007). A high population turnover reflects weak community links, a lack of identification with the neighbourhood and anonymity. There is evidence of a correlation between high mobility and violence and crime (Sampson \& Groves, 1989; Sampson et al., 1997). People who move to a neighbourhood without the intention to stay long are unlikely to invest in a network of contacts or to participate in neighbourhood activities. A high population turnover, in combination with selective mobility, can also be part of the spiral of decline (Andersson \& Bråmå, 2004). An exodus of the better off and influx of people with a lower socio-economic status drives the neighbourhood further towards decline (Friedrichs, 1991; Power, 1997; Skifter Andersen, 2002). Lee and colleagues (1994) included an objective and a subjective measure of neighbourhood population mobility in their models of mobility thoughts and actual mobility on data from Nashville Tennessee. They found that the higher the mobility rate in a neighbourhood (percentage of recent movers), the less likely people were to have mobility thoughts. This result is counterintuitive and might be caused by bias in the very small sample they used. In their model of actual mobility they found that residents who perceived a high population turnover were more likely to move. Based on the above we hypothesised that people are more likely to have the wish to leave their neighbourhood in neighbourhoods with a high population turnover (hypothesis 3 ).

\section{Known factors influencing moving wishes}

Several factors are known to influence moving wishes and we need to control for those in our analysis of the wish to leave the neighbourhood. The first set of control variables are personal and household characteristics: age, household composition, income, level of education, ethnicity and recent mover status (see Morris et al., 1976; Varady, 1989; Kearns \& Parkes, 2003; Van Ham \& Feijten, 2008). The second set of control variables are characteristics of the dwelling. Although we are analysing the wish to leave the neighbourhood it can be expected that dwelling characteristics (tenure and type) and dwelling satisfaction are important predictors. Those who are perfectly happy with their dwelling can be expected to be less likely to state that they want to leave their neighbourhood. Even when the neighbourhood does not perfectly match their preferences and needs, being satisfied with the dwelling is likely to compensate for this. Owners and residents of single family dwellings can be expected to be the least likely to express a wish to leave their neighbourhood because they are more likely to have selected themselves into 
more desirable neighbourhoods. This is partly because owner occupied dwellings and single family dwellings are generally located in more desirable neighbourhoods and partly because owners are more likely than renters to be in a phase in their life course where they have sorted themselves into a neighbourhood in line with their preferences and needs.

Some models of moving wishes (or intentions) also include static neighbourhood characteristics (e.g. Lee et al., 1994; Kearns \& Parkes, 2003; Van Ham \& Feijten, 2008). There is some debate on the effect of static neighbourhood characteristics on the mobility decision making process. People's sorting into neighbourhoods is not based on a random process as people select themselves into neighbourhoods based on known (perceived) neighbourhood characteristics (see Manski, 1993; Moffitt, 1998; Brock \& Durlauf, 2003; Durlauf, 2004, for a more technical discussion). This selective sorting is likely to cause models to underestimate the 'real' effect of static neighbourhood characteristics on the wish to leave their neighbourhood because those people most likely to be affected by these neighbourhood characteristics have not moved into these neighbourhoods in the first place. There are several reasons why static neighbourhood characteristics can affect the wish to leave the neighbourhood (see Van Ham \& Clark, forthcoming). First, due to imperfect information upon arrival in a neighbourhood, negative aspects of a neighbourhood might only reveal themselves after some length of time. Second, people's needs and desires change over time, which might have an effect on how people see their neighbourhood. Third, not all people end up in the neighbourhood of their choice. For most people a suitable dwelling will be the first priority, and they will accept it even when the dwelling is located in a less desirable neighbourhood. Fourth, the choice to live in a highly mobile or deprived neighbourhood can be a positive choice connected with a certain phase in the life course and people might expect to move out of the neighbourhood soon again.

In previous work (Van Ham \& Feijten, 2008) we examined the effects of a series of static neighbourhood characteristics on the wish to leave the neighbourhood. The results showed that especially people in neighbourhoods with a high percentage of non-western ethnic minorities were likely to have the wish to leave. This might be a direct effect caused by, for example, discrimination, but it might also be an indirect effect. It is likely that the presence of ethnic minorities stands for other negative factors in the neighbourhood that are not measured in our data, but which make people want to leave the neighbourhood (the racial proxy hypothesis, see Clark, 1992; Harris, 1999; Taub et al., 1984). Our results, however, seemed to point in the direction of discrimination as our analysis lends some support to the hypothesis based on Schelling's (1969, 1971; Clark, 1991) work that, when people's own characteristics match the characteristics of the neighbourhood population, they are less likely to want to leave their neighbourhood. In other words, we found that a high percentage of non-western ethnic minorities only had an effect on the native population's wish to leave the neighbourhood. We also found that the neighbourhood tenure mix had an effect on people's wish to leave their neighbourhood (see also Lee et al., 1994). The higher the percentage of renters, the higher the probability people have a wish to leave their neighbourhood. Again, in line with Schellings's hypothesis we found that renters in neighbourhoods with a high percentage of renters were less likely to have a wish to move than owners in these neighbourhoods.

\section{Data and method}

To test our hypotheses, we used data at both individual and neighbourhood level. The individual-level data (75,043 respondents) were assembled from the 2002 Housing Demand Survey (WBO) of the Ministry of Housing, Spatial Planning and the Environment (VROM), 
which is available through the Netherlands Scientific Statistical Agency. The research sample was representative of the Netherlands' population aged 18 and over and not living in an institution. For the analysis, respondents between the ages of 18 and 80 were selected, excluding people still living with their parents, people living in shared housing such as student accommodation, and people living in non-house accommodation such as boats or trailers. Further, we excluded people living in the most sparsely populated areas (fewer than 500 addresses per square kilometre). Following this selection, the research sample consisted of 52,403 respondents.

We used respondents' 4-digit postcode to link neighbourhood level data to individual respondents. We are aware that there is no one-to-one relationship between 4-digit postcode areas and neighbourhoods as perceived by residents (see Galster, 2001). However, in urban areas, 4-digit postcodes come close to what people may perceive as their neighbourhood, as urban postcodes are relatively small in size (one square kilometre or less). This is why we excluded respondents in the most sparsely populated areas as for them, postcodes cover areas which we perceived too large to be considered a neighbourhood. When postcodes with less than 500 addresses per square kilometre are excluded, the average postcode has a population of 6,741 residents.

The neighbourhood level data were assembled from several sources. We used four neighbourhood-level variables from the ABF Combimonitor. The first is the percentage of non-western ethnic minorities in 1998 and 2002 (original source CBS - Population statistics). Non-western ethnic minorities are defined as people with at least one parent born in Africa (of these, Moroccans are the largest group), Asia (excluding Japan and Indonesia, which belonged to the Netherlands Kingdom until 1949), Latin America, Turkey, Surinam, or the Netherlands Antilles. The second is the percentage of rented dwellings in 2002 (original source ABF Research - SysWov). We combined private and social renting in one category. The third is the degree of urbanisation of the postcode (original source CBS Postcode Register), which was measured as address density in four categories, ranging from 500-1,000 addresses per square kilometre to more than 2,500 addresses per square kilometre. The fourth variable is the percentage of residents in a neighbourhood who were subject to urban renewal in 1998 (original source Woonmilieudatabase Cebeon). Based on information supplied by the Ministry of Housing it was calculated which percentage of the population in a postcode was subject to urban renewal projects.

We used neighbourhood level socio-economic status scores for 1998 and 2002 from the Netherlands Institute for Social Research (SCP, 1998). The scores were developed by applying Principal Component Analysis on three neighbourhood indicators (on the 4-digit postcode level): mean educational level, mean income and mean unemployment rate. This procedure resulted in a rank order score of all postcodes by socio-economic status (with a mean of zero when all postcodes are used). We recoded the original variable so that a high (positive) score refers to a high socio-economic score and a low (negative) score refers to a low socio-economic score. Data on the percentage of people who moved within or out of a neighbourhood in 2002 (population turnover) was bought from Statistics Netherlands (CBS) and originated from the Netherlands Municipal Personal Records Database (Gemeentelijke Basis Administratie, GBA). The correlation matrix of the neighbourhood-level variables (not shown) did not show alarming levels of collinearity.

Table 1 presents the summary statistics and definitions of the variables used in our study. For the dependent variable we used a direct measure of people's wish to leave the neighbourhood, based on the survey question: 'if possible, would you like to leave the neighbourhood?' The resulting dependent variable is dichotomous and indicates whether (1) or not (0) respondents have the wish to leave their neighbourhood. In total 19.9 percent of the respondents in our sample have the wish leave their neighbourhood (see Table 1). We 
included several types of control variables as mentioned in the literature review: individual characteristics; household characteristics; characteristics of the dwelling; and static neighbourhood characteristics. We included the following objective measures of neighbourhood change: socio-economic status change between 1998 and 2002; change in the percentage of non-western ethnic minorities between 1998 and 2002; and the percentage of people who moved in 2002. We also included a subjective personal opinion about neighbourhood change, which was measured using the following question: "Do you find that the neighbourhood where you live has, in the last year... (1) improved (2) deteriorated (3) remained the same?".

\section{---- Please insert Table 1 about here ----}

\section{Method}

We used logistic regression to model whether (1) or not (0) respondents have a wish to leave their neighbourhood. Because the data contains more than one respondent per postcode, a simple logistic regression model would violate the standard assumption of the independence of observations. This clustering of data is handled by using a multilevel model. The model used has two levels: the individual level and the postcode level (see Van Ham \& Feijten, 2008 , for more details on the model used). The model allows for the inclusion of interactions between individual characteristics and neighbourhood characteristics (cross-level interactions). In the model, the intercept is assumed to vary randomly across individuals and neighbourhoods, but the relationship between the dependent and the independent variables is assumed to be the same for all individuals within a neighbourhood. This type of model is known as a random effects model or random intercept model (Snijders \& Bosker, 1999). It was decided to use a random effects model instead of a fixed effects model, because it allows us to test the effects of neighbourhood-level variables, whereas a fixed effects model would capture all differences between neighbourhoods in its fixed effects (Snijder \& Bosker, 1999). To assess the fit of our models, we carried out Wald tests (models with covariates only).

A classic problem with the type of study reported in this paper is omitted variable bias (see Moffitt, 1998; Van Ham \& Feijten, 2008 for a detailed discussion related to the wish to move). The omitted-context-variables problem, also called the correlated unobservables problem, arises if important characteristics of the context are omitted from the regression and these unobserved variables (at the neighbourhood level) are correlated with included variables. In the case of our models, unmeasured characteristics of neighbourhoods (including change) can be correlated with the change variables included in the models. This is most likely to affect the parameter of the changes in the percentage of non-western ethnic minorities in the neighbourhood variable (see Harris, 1999). For example, neighbourhoods where there is an increase in ethnic minorities might also experience a change in local public services or other amenities associated with the neighbourhood. It might very well be that these variables are the 'real' underlying cause of people's wish to leave the neighbourhood and not the change in ethnic composition. It is impossible to know (as in all social science research) whether all relevant variables are controlled for. However, since we do control for the (change in) socio-economic status of neighbourhoods - the most important control variable mentioned in the literature (see Harris, 1999) - it is unlikely that any effect found of change in ethnic composition is simply a proxy for the effect of a change in the socioeconomic status of neighbourhoods (see also Van Ham \& Feijten, 2008; Van Ham \& Clark, forthcoming). We also control for other neighbourhood characteristics which we believe together form a meaningful summary of (change in) neighbourhood conditions. 


\section{Analysis}

\section{Multivariate results}

Table 2 shows the results of a series of 5 multilevel logistic regression models estimating people's wish to leave the neighbourhood. An extra set of variables is added in each consecutive model. The first model (Model 0) is an intercept-only model and includes no explanatory variables; Model 1 includes a set of individual and household variables, dwelling characteristics and static neighbourhood characteristics; Model 2 includes a subjective indicator of neighbourhood change, namely the respondent's personal opinion; Model 3 includes objective neighbourhood change variables, but not the subjective variable; and model 4 includes both the personal and the objective measures of neighbourhood change. At the bottom of the Table, a Wald diagnostic is given for each model, indicating the model fit improvement compared to the previous nested model.

\section{---- Please insert Table 2 about here ----}

Model 0 only includes a constant and allows to decompose the total variance into the individual and the neighbourhood level by calculating the intra-class correlation (ICC) coefficient. This coefficient is calculated from the random variance at the neighbourhood level (0.246) and the variance of a logistic distribution with scale factor 1 (3.29) (see Rasbash et al., 2004). The intra-class correlation coefficient of $7 \%(0.246 /[0.246+3.29])$ informs of an appreciable level of clustering of individual moving wishes within neighbourhoods (compare Merlo et al., 2005; see also Snijders \& Bosker, 1999). We can therefore carefully conclude that potentially some of the variation in moving wishes can be explained by neighbourhood characteristics and measures of neighbourhood change. Alternatively, this neighbourhood level effect might be attributable to variation in population composition between neighbourhoods. In Model 1, a set of personal, household, dwelling and static neighbourhood characteristics are added to the model. The variance at the neighbourhood level decreased strongly from 0.246 to 0.062 . About two third of this decrease is caused by the individual and household characteristics, indicating that the difference in moving wishes between neighbourhoods is largely explained by composition effects of the population. The other one third of the drop is caused by the static neighbourhood characteristics.

In Model 1 the effect of age on moving wishes is negative and the effect of agesquared is positive, indicating that, as expected, people are less likely to consider leaving their neighbourhood with increasing age, but as people become very old they are slightly more likely to have the wish to leave their neighbourhood. Compared to singles, lone parent household and couples without children are more likely to have a wish to leave their neighbourhood (including the very heterogeneous category of 'other households'). Couples with children are not more likely than singles to have the wish to leave their neighbourhood. Although it can be expected that families with children have a long wish list considering the neighbourhood and the type of residential environment, many of them might already have managed to realise most of their wishes. The effect of income on moving wishes is small and insignificant. The probability that people want to leave their neighbourhood increases with level of education. The effect of belonging to a non-western ethnic minority group is not significant. Recent movers are less likely to have the wish to leave their neighbourhood than those who did not move recently. The most likely explanation is that recent movers have chosen their neighbourhood based on current characteristics while those who have lived in 
the neighbourhood for a longer time made their decision based on past characteristics which might not match their preferences and needs as closely anymore.

The effects of many of the personal and household variables are relatively modest compared to those of the characteristics of the dwelling. This is probably because the effects of personal and household characteristics are partly taken away by the characteristics of their dwelling, because we know that people's housing circumstances are closely related to income, education and ethnicity (Michelson, 1977; Clark \& Dieleman, 1996). Living in a rental dwelling (compared to an owner-occupied dwelling) increases the probability that people want to leave their neighbourhood. Those living in a single-family dwelling are less likely to have the wish to leave the neighbourhood than those living in a flat or shared accommodation. Finally, and as expected, housing satisfaction has a very strong effect on moving wishes. People who are satisfied with their dwelling are far less likely to have a wish to leave their neighbourhood than people who are neutral or dissatisfied. Housing satisfaction is a good proxy for unmeasured housing characteristics that affect moving wishes. The results show that the wish to leave the neighbourhood cannot be seen separately from housing characteristics.

Model 1 also includes several static neighbourhood characteristics. With increasing degree of urbanisation, people are more likely to have the wish to leave their neighbourhood (except for people in the very strongly urbanised areas, who are the least likely to have a wish to leave their neighbourhood). The effect of socio-economic status of the neighbourhood is straightforward: the higher the status score, the lower the probability that residents wish to leave their neighbourhood. With increasing percentage of non-western ethnic minorities in the neighbourhood, the probability that people want to leave increases. Although the parameter of 0.018 seems rather small, this parameter indicates the increase in probability per percent point (remember that some postcode areas have 85 percent nonwestern ethnic minorities). The interaction effect between individual ethnicity and the ethnic composition of the neighbourhood shows that for people from non-western origin themselves there is hardly any effect of the ethnic composition of the neighbourhood as the interaction effect almost counterbalances the main effect of percentage non-western residents. Although the main effect of the percentage of rented dwellings in the neighbourhood does not have a significant effect on moving wishes, the interaction effect with own tenure is significant. For renters, the percentage of rented dwellings in the neighbourhood has a negative effect on the wish to leave the neighbourhood. The interaction effect (-0.004) is very small in comparison to the main individual effect (0.339). Only in neighbourhoods with a very high percentage of rented dwellings $(>85 \%)$ the interaction effect outweighs the individual effect. The effect of both interaction effects support the hypothesis based on Schelling's $(1969,1971)$ work that, when people's own characteristics match the characteristics of the neighbourhood population, they are less likely to want to leave their neighbourhood (see also Van Ham \& Feijten, 2008).

In Model 2, we add the first indicator of neighbourhood change to our model: the subjective individual opinion on neighbourhood change. The variance at the neighbourhood level decreased from 0.062 to 0.056 , and the model improvement is significant (increase in Wald is 479.13 with $2 \mathrm{df}$ ). The results show that compared to people who feel their neighbourhood has not changed or has improved, those who feel that the neighbourhood has deteriorated have a much higher probability of wishing to leave the neighbourhood. It is interesting to see that this effect (0.847) is not as strong as the effect of being unsatisfied with the dwelling (-1.484), which is also a dummy and therefore directly comparable. In addition to this difference in the size of the effects, the size of the groups affected also differs considerably. Almost 16 percent of the respondents stated that their neighbourhood has deteriorated, compared to more than 88 percent who stated that they are satisfied with their 
dwelling. Thus, on the level of neighbourhoods, the negative effect of satisfaction with the dwelling has a much bigger impact on moving wishes than the positive effect of subjective neighbourhood change.

In Model 3 the subjective measure of neighbourhood change is left out of the model, but several objective measures of change are included: change in percentage of non-western ethnic minorities, change in socio-economic status of the neighbourhood (both over the period 1998-2002), population turnover in 2002, and percentage of neighbourhood residents who were subject to urban renewal in 1998. The variance at the neighbourhood level decreased from 0.056 (in Model 1) to 0.050. The model fit improvement is significant compared to Model 1 (increase in Wald is 149.36 with $6 \mathrm{df}$ ). The objective measures of neighbourhood change explain about the same amount of variance at the neighbourhood level as the subjective individual opinion about neighbourhood change. An increase of neighbourhood socio-economic status has a negative effect on the wish to leave the neighbourhood: if the socio-economic status of a neighbourhood improves, people want to stay. Remarkably, a decrease in neighbourhood socio-economic status does not lead to a wish to leave the neighbourhood. An increase in the percentage of non-western ethnic minorities in a neighbourhood between 1998 and 2002 has a positive effect on people's wish to leave their neighbourhood. We also tested an interaction effect between own ethnicity and change in the percentage of ethnic minorities, but the effect was not significant.

Population turnover in the neighbourhood (measured as the percentage of people who moved in 2002) has a positive effect on people's wish to leave their neighbourhood. Again remember that population turnover is measured in percentages, so the effect is actually quite strong. In fact, it is stronger than the effect of a change in the percentage of non-western ethnic minorities. A high population turnover in the neighbourhood may mean several things. First it could be a symptom of problems in the neighbourhood not very well measured by the variables in our model. But high population turnover itself can also cause problems. It can be expected that social networks deteriorate when many people leave the neighbourhood, which may cause sitting residents to develop a wish to leave their neighbourhood. Also, those who move into the neighbourhood might have very different characteristics (age, household composition or otherwise) compared to the out-migrants, which may trigger the wish to leave for sitting residents. Lastly, there may be an element of 'contamination' that explains the relatively strong effect. When residents see many of the people around them moving, this may inspire them to consider a move themselves.

The final variable added to Model 3 measures the percentage of neighbourhood residents who were subject to urban renewal in 1998. This is a measure of the extent of policy driven neighbourhood change. The results show that people living in neighbourhoods where over 50 percent of the population was subject to urban renewal are less likely to have the wish to leave their neighbourhood compared to those living in other neighbourhoods. The most likely explanation is that people who live in urban renewal neighbourhoods experience (or expect) mainly positive change and therefore want to stay. This is confirmed by the results from a cross tabulation of the percentage of people subject to urban renewal in the neighbourhood and personal opinion about neighbourhood change (results not shown). This cross tabulation shows that the higher the percentage of people subject to urban renewal in a neighbourhood, the higher the percentage of people stating that their neighbourhood has improved over the last year.

To assess how much effect the significant (at $\mathrm{p}<0.01$ ) change variables in Model 3 have on the probability to wish to leave the neighbourhood, we simulated the risk to have a moving wish for varying levels of change in the percentage of non-western ethnic minorities and neighbourhood population turnover (not shown). The results for an average respondent show that the effect of both change variables on the risk of a wish to move is roughly the 
same. A ten percent-point increase in ethnic minorities leads to an increase in the risk to have a moving wish of around 0.025. A ten percent increase in the number of households that has moved leads to an increase in the risk to have a moving wish of around 0.03 . Given that the average predicted risk in the sample is 0.16 (ranging from 0.03 to 0.85 ), it can be said that both change variables have a moderate contribution.

Finally, Model 4 includes both the (subjective) individual-level and (objective) neighbourhood-level change variables. This model has the best model fit and is a significant improvement compared to both Models 2 and 3. Compared to Model 3 there is a further small decrease in the unexplained variance at the neighbourhood level. Again, the subjective change indicator shows that those who find that their neighbourhood has deteriorated are more likely to have a wish to leave their neighbourhood. However, compared to model 3, the parameters of the change in socio-economic status and the percentage-point change of nonwestern ethnic minority residents decreased and lost their significance. We carefully conclude from this finding that when people are asked whether they think their neighbourhood has changed in the last year, it is change in socio-economic status and proportion of non-western ethnic minority residents that they have in mind (apart from other things not measured in our analysis). The fact that the effect of population turnover hardly changed when personal opinion about neighbourhood change was included, indicates that people do not necessarily equal a high mobility rate in their neighbourhood to neighbourhood deterioration. Interestingly a high population turnover has an independent effect on people's wish to leave the neighbourhood. Apparently, although people might not link a high population turnover to neighbourhood deterioration, it does trigger the wish to leave. This is possibly the case because a high population turnover corrodes the social cohesion in the neighbourhood or stands for other, unmeasured, features of the neighbourhood that increase the wish to leave among many residents.

\section{Conclusion and discussion}

The results show that both static neighbourhood characteristics and subjective and objective indicators of neighbourhood change have a significant effect on people's wish to leave their neighbourhood. People who perceive a decline in their neighbourhood are more likely to have a wish to leave. People who live in a neighbourhood with an increase in socioeconomic status are less likely to have a wish to leave and people who live in a neighbourhood with an increase in the percentage of ethnic minorities and a high population turnover are more likely to have a wish to leave. It is very interesting to see that the effects of a change in the percentage of non-western ethnic minorities and socio-economic change disappear when controlled for residents' subjective opinion about neighbourhood change. This might indicate that people associate an increase in the percentage of ethnic minorities and a decreasing socio-economic status with neighbourhood decline.

The former raises important questions on the meaning of the ethnic component of neighbourhood change. The racial proxy hypothesis argues that the neighbourhood ethnic composition stands for a whole range of other socio-economic indicators on the neighbourhood level and that it is not ethnicity per se which causes people to want to leave the neighbourhood. The hypothesis also argues (Harris, 1999) that the effect of ethnicity will disappear when non-racial neighbourhood characteristics are added to the model. Our models show that both the static variable on neighbourhood ethnic composition and the indicator on neighbourhood ethnic change still significantly contribute to the model after controlling for (change in) neighbourhood socio-economic status. Although it is clear that there are many other non-ethnic neighbourhood characteristics that ideally could have been 
included (if available) in the model, our results indicate that (change in) ethnic composition of the neighbourhood it not a pure proxy for (change in) socio-economic status. Therefore we believe, as discussed in the methods section, that our results do not systematically suffer from omitted variable bias.

To get more insight in the role of other neighbourhood characteristics in understanding mobility, more objective data on the neighbourhood level is needed, such as information on garbage on the street, crime, and physical neighbourhood deterioration. Unfortunately such data is hard to obtain on a low spatial level for a whole country. Another way to get more insight in the role of the neighbourhood in residential mobility decisions would be to study a few neighbourhoods closely for a number of years. Through observation, interviews with residents (old and new) and key informants, and keeping track of migration statistics, a more integrated picture of residents' preferences, needs and objectives with regard to neighbourhoods and the effects of neighbourhood change could be obtained. It would also be a unique opportunity to examine whom of those who express a wish to leave actually succeed in leaving, and whether there are time lags involved. Of those who do not succeed it would be interesting to know whether they stayed because they had no alternatives, or because they changed their mind for some reason. Such a research project would, however, be very costly and time consuming, and the results would not be available before a few years.

Although we used a variable which measures directly people's wish to leave the neighbourhood, our results have shown that it is unavoidable that this variable also measures general moving wishes. This might explain a number of our outcomes, for example, the effect of the control variable age. It also explains the very strong effect of being satisfied with the dwelling. The results suggests that while answering the question whether one would prefer to leave the neighbourhood, feelings about the dwelling interfere: dwelling and environment around the dwelling are strongly interwoven and are clearly not experienced as completely separate entities.

We are aware that the spatial units used as proxies for neighbourhoods in this study might be very different from how individuals experience their neighbourhood. It is likely that what people experience as their neighbourhood is often a smaller area than the statistical unit we used, for example the streets right around their house. Alternatively the perceived neighbourhood might be larger than the statistical unit (bordered by landmarks such as major roads, waterways, green areas or houses from a different building period). Yet, we think we should not abandon this type of study solely for the reason that 'neighbourhoods' are hard to define. We believe that our results probably underestimate the real effect of neighbourhood change (see for example Van Ham \& Manley, 2008), rather than being meaningless as some would argue. Qualitative studies focusing on one area and using respondents' definitions of 'their' neighbourhood have yielded very valuable insights, but lack the scale to generalise findings. Our study covers a whole country and therefore allows us to compare a large variety of neighbourhoods, enabling us to show that neighbourhood change influences people's wish to leave their neighbourhood. More longitudinal neighbourhood research could fill the lacunas in our knowledge of neighbourhoods and their residents, which is important as "a deeper understanding of how people perceive and respond to change is required if we are to improve the liveability of cities" (Aitken, 1990, p. 263).

\section{Acknowledgements}

The authors gratefully acknowledge the financial support of the British Academy to present an earlier version of this paper at the 4th International Population Geographies Conference 2007 in Hong Kong. Further, we would like to thank the editors of Urban Studies, and the anonymous referees for their useful comments on an earlier version of this paper. Peteke 
Feijten also worked on this paper while she was employed at the Netherlands Institute for Spatial Research (RPB), The Hague, The Netherlands.

\section{References}

Aitken, S.C. (1990) Local evaluations of neighborhood change, Annals Of The Association of American Geographers, 80(2), pp. 247-267.

Andersson, R. and Bråmå A. (2004) Selective migration in Swedish distressed neighbourhoods: can area-based urban policies counteract segregation processes?, Housing Studies, 19(4), pp. 517-539.

Auletta, K. (1982) The Underclass. New York, Random House

Bailey N. and Livingston, M. (2007) Population turnover and area deprivation, The Policy Press, Bristol.

Bobo, L. and Zubrinsky, C.L. (1996) Attitudes on residential integration: perceived status differences, mere in-group preference, or racial prejudice?, Social Forces, 74(3), pp. 883-909.

Boehm, T.P. and Ihlanfeldt, K.R. (1986) Residential mobility and neighborhood quality, Journal of Regional Science, 26, pp. 411-24.

Bonaiuto, M., Aiello, A., Pergugini, M., Bonnes, M. And Paola Ercolani, A. (1999) Multidimensional perception of residential environment quality and neighbourhood attachment in the urban environment, Journal of Environmental Psychology, 19(4), pp. 331-352.

Bonaiuto, M., Fornara, F. and Bonnes, M. (2003) Indexes of perceived residential environment quality and neighbourhood attachment in urban environments: a confirmation study on the city of Rome. Landscape and Urban Planning, 65(1-2), pp. 41-52.

Brock, W.A. and Durlauf, S.N. (2005) Multinomial Choice with Social Interactions, in: Blume, L., Durlauf, S.N. (Eds.) The Economy as an Evolving Complex System III: Current Perspectives and Future Directions, Oxford University Press. pp 175-206.

Brown, L.A. and Moore, E.G. (1970) The intra-urban migration process: a perspective, Geografiska Annaler Series B, 52, pp. 1-13.

Clark, W. A. V. and Onaka, J. L. (1983) Life Cycle and Housing Adjustment as Explanations of Residential Mobility, Urban Studies, 20(1), pp. 47-57.

Clark, W.A.V. (1991) Residential preferences and neighborhood racial segregation - a test of the Schelling segregation model, Demography, 28, pp. 1-19

Clark, W.A.V. (1992) Residential preferences and residential choices in a multiethnic context. Demography, 29, pp. 451-466.

Clark, W.A.V. and Dieleman, F.M. (1996) Households and Housing: Choices and Outcomes in the Housing Market. New Brunswick, NJ: Center for Urban Policy Research.

Clark, W.A.V., Deurloo, R.C., and Dieleman, F.M. (2004) Choosing neighborhood: residential mobility and neighborhood careers. ENHR Conference paper.

Crowder, K. (2000) The racial context of white mobility: An individual-level assessment of the white flight hypothesis, Social Science Research, 29, pp. 223-257.

Cybriwsky, R.A. (1978) Social aspects of neighbourhood change, Annals of the Association of American Geographers, 68, pp. 17-33.

De Groot, C., Manting, D., and Mulder, C. H. (2007) Intentions to move and actual moving behaviour in the Netherlands. Paper for the 2007 European Network for Housing Research (ENHR) Conference, Rotterdam.

Durlauf, S.N. (2004) Neighbourhood effects, in: Henderson, J.V. and Thisse, J.F. (Eds.) Handbook of Regional and Urban Economics. Volume 4 Cities and Geography, Elsevier, Amsterdam. pp 2173-2242. 
Friedrichs, J. (1991) Middle-class leakage in large new housing estates: empirical findings and policy implications, Journal of Architectural and Planning Research, 8, pp. 287295.

Galster, G. (1987) Homeowners and neighborhood reinvestment, Duke University Press.

Galster, G. (2001) On the nature of neighbourhood, Urban Studies, 38, pp. 2111-2124.

Gould Ellen, I. (2000) Race-based neighbourhood projection: a proposed framework for understanding new data on racial integration, Urban Studies, 37(9), pp.1513-1533.

Harris, D.R. (1999) "Property values drop when blacks move in, because...": racial and socioeconomic determinants of neighborhood desirability, American Sociological Review, 64(3), pp. 461-479.

Huff, J.O. and W.A.V. Clark (1978) Cumulative stress and cumulative inertia: a behavioral model of the decision to move, Environment and Planning A, 10(10), pp. 1101-1119.

Jencks, C. (1992) Rethinking Social Policy: Race, Poverty, and the Underclass. Cambridge, MA: Harvard University Press.

Katz, M.B. (1989) The undeserving poor: from the war on poverty to the war on welfare. New York: Pantheon Books.

Kearns, A. and Parkes, A. (2003) Living in and leaving poor neighbourhood conditions in England, Housing Studies, 18, pp. 827-851.

Lee, B.A., Oropesa, R.S. and Kanan, J.W. (1994) Neighborhood context and residentialmobility, Demography, 31(2), pp. 249-270.

Lu, M. (1998) Analyzing migration decision making: Relationships between residential satisfaction, mobility intentions, and moving behaviour, Environment and Planning $A$ 30(8): 1473-1495.

Manski, C. (1993) Identification of endogenous social effects: The reflection problem, Review of Economic Studies, 60, pp. 531-542

Mayer, A. (1960) Russell Woods: Change Without Conflict: A Case Study of Neighbourhood Transition in Detroit, in: N. Glazer and D. McEntire (eds.) Studies in Housing and Minority Groups, Univ. of California Press, Berkeley. pp. 198-220.

Merlo, J., Chaix, B., Yang, M., Lynch, J. and Råstam, L. (2005) A brief conceptual tutorial of multilevel analysis in social epidemiology: linking the statistical concept of clustering to the idea of contextual phenomenon, Journal of Epidemiology and Community Health, 59 , pp. 443-449.

Michelson, W. (1977) Environmental Choice, Human behavior, and Residential Satisfaction. New York: Oxford University Press.

Moffitt, R. (1998) Policy interventions, low-level equilibria, and social interactions, Johns Hopkins University, Department of Economics, Economics Working Paper Series number 432.

Molotch, H. (1969) Racial change in a stable community, American Journal of Sociology, 75, pp. 226-238.

Morris, E.W., Crull S.R. and Winter, W. (1976) Housing norms, housing satisfaction and the propensity to move, Journal of marriage and the family, 38, pp. 309-320.

Mulder, C.H. and Hooimeijer, P. (1999) Residential relocations in the life course. In: Wissen, L.J.G. and Dykstra, P.A. (Eds.) Population Issues. An interdisciplinary focus, pp. 159-186. New York: Kluwer Academic/Plenum Publishers.

Parkes, A., Kearns, A. and Atkinson, R. (2002) What makes people dissatisfied with their neighbourhoods?, Urban Studies, 39(13), pp. 2413-2438.

Parkes, A. and Kearns, A. (2003) Residential perceptions and housing mobility in Scotland: An analysis of the longitudinal Scottish House Condition Survey 1991-96, Housing Studies, 18, pp. 673-701. 
Permentier, M., Van Ham, M. and Bolt, G. (2007) Behavioural responses to neighbourhood reputations, Forthcoming in Journal of Housing and the Built Environment.

Power, A. (1997) Estates on the Edge. The Social Consequences of Mass Housing in Northern Europe, London, MacMillan.

Rapkin, C. and Grigsby, W. (1960) The Demand for Housing in Racially Mixed Areas, University of California Press, Berkeley, CA.

Rasbash, J., Steele, F., Browne, W. and Prosser, B. (2004) A user's guide to MLwiN version 2.0, Institute of Education, London.

Rossi, P. H. (1955) Why families move. A study in the social psychology of urban residential mobility, Free Press, Glencoe, Illinois.

Sabagh, G., Van Arsdol Jr, M.D. and Butler, E.W. (1969) Some determinants of intrametropolitan residential mobility: conceptual considerations, Social Forces, 48, pp. 9898.

Sampson, R.J. \& Groves, W.B. (1989) Community structure and crime: testing socialdisorganisation theory, American Journal of Sociology, 94, pp. 774-802.

Sampson, R.J., Raudenbush, S.W. \& Earls, F. (1997) Neighborhoods and violent crime: a multilevel study of collective efficacy, Science, 277, pp. 918-924.

Schelling, T.C. (1969) Models of segregation, The American Economic Review, 59, pp. 488493

Schelling, T.C. (1971) Dynamic models of segregation, Journal of mathematical sociology, 1, pp. 143-186.

SCP (1998) Van hoog naar laag; van laag naar hoog. Rijswijk: Sociaal en Cultureel Planbureau, Cahier nr. 152.

Shevsky, E. and Bell, W. (1955) Social area analysis. Stanford, CA: Stanford University.

Skifter Andersen, H. (2002) Urban Sores: On the Interaction between Segregation, Urban Decay and Deprived Neighbourhoods, Aldershot, Ashgate.

Skogan, W.G. (1990) Disorder and Decline: Crime and the Spiral of Decay in American Neighborhoods. New York: Free Press.

Snijders, T.A.B. and Bosker, R.J. (1999) Multilevel analysis: An introduction to basic and advanced multilevel modelling (Sage, London).

Speare, A., Goldstein, S. and Frey, W.H. (1975) Residential mobility, migration, and metropolitan change, Ballinger, Cambridge Mass.

Speare Jr., A. (1974) Residential Satisfaction as an Intervening Variable in Residential Mobility, Demography, 11(2), pp. 173-188.

Taub, R.P., Taylor, G.D. and Dunham, J.D. (1984) Paths of Neighborhood Change. Chicago, IL: University of Chicago Press.

Van Beckhoven, E. (2006) Decline and Regeneration: Policy responses to processes of change in post-WWII urban neighbourhoods, (Vol. 346), Utrecht: KNAG/Faculteit Geowetenschappen Universiteit Utrecht.

Van Ham, M. and P. Feijten (2008) Who wants to leave the neighbourhood? The effect of being different from the neighbourhood population on wishes to move, Environment and Planning A, 40, pp. 1151-1170.

Van Ham, M. and Manley, D. (2008) The Effect of Neighbourhood Housing Tenure Mix on Labour Market Outcomes: A Longitudinal Perspective. Paper for the 2008 European Network for Housing Research (ENHR) Conference, Dublin.

Van Ham, M. and W.A.V. Clark (Forthcoming) Neighbourhood mobility in context: household moves and changing neighbourhoods in the Netherlands, Environment and Planning A. 
Van Vught, M., Dowding, K., John, P. and Van Dijk, E. (2003) The exit of residential mobility or the voice of political action? Strategies for problem solving in residential communities, Journal of applied social psychology, 33(2), pp. 321-338.

Varady, D.P. (1989) The impact of city/suburban location on moving plans: a Cincinnati study, Growth and Change, 20, pp. 35-49.

Wilson, W. (1987) The truly disadvantaged. The inner city, the underclass and public policy, University of Chicago Press, Chicago.

Wolf, E.P. (1957) The invasion-succession sequence as a self-fulfilling prophecy, Journal of Intergroup Relations, 3, pp. 75-81.

Wolf, E.P. (1963) The tipping-point and racially changing neighborhoods, Journal of the American Institute of Planners, 29, pp. 217-222.

Wolpert, J. (1966) Migration as an adjustment to environmental stress, Journal of Social Issues, 12, pp. 92-102. 
TABLE 1. Means and frequencies of variables $(\mathrm{N}=52,403)$

\begin{tabular}{|c|c|c|}
\hline Means & Mean & S.d. \\
\hline Age & 46.52 & 15.5 \\
\hline Age squared/mean age & 51.57 & 33.1 \\
\hline Disposable household income in 10,000 euros & 28.84 & 19.2 \\
\hline Socio-economic status score 2002 (neighbourhood) & -0.21 & 1.0 \\
\hline Percentage non-western ethnic minorities 2002 & 11.46 & 12.4 \\
\hline Percentage rented dwellings 2002 & 48.16 & 18.5 \\
\hline Percentage-point change non-western ethnic minorities 1998-2002 & 2.26 & 2.8 \\
\hline Percentage of neighbourhood population moved in 2002 & 10.55 & 3.7 \\
\hline Frequencies & $\mathrm{N}$ & $\%$ \\
\hline \multicolumn{3}{|l|}{ Wish to leave the neighbourhood } \\
\hline no & 41,975 & 80.1 \\
\hline yes & 10,428 & 19.9 \\
\hline \multicolumn{3}{|l|}{ Household composition } \\
\hline one person household & 13,739 & 26.2 \\
\hline couple without children & 17,301 & 33.0 \\
\hline couple with children & 16,937 & 32.3 \\
\hline Ione parent family & 3,044 & 5.8 \\
\hline other & 1,382 & 2.6 \\
\hline \multicolumn{3}{|l|}{ Highest completed level of education } \\
\hline low & 14,617 & 27.9 \\
\hline middle & 23,487 & 44.8 \\
\hline high & 14,299 & 27.3 \\
\hline \multicolumn{3}{|l|}{ Non-Western ethnicity } \\
\hline Western ethnicity & 47,561 & 90.8 \\
\hline non-Western ethnicity & 4,842 & 9.2 \\
\hline \multicolumn{3}{|l|}{ Recent mover status } \\
\hline did not move last year & 45,686 & 87.2 \\
\hline moved last year & 6,717 & 12.8 \\
\hline \multicolumn{3}{|l|}{ Tenure } \\
\hline owner-occupied & 28,282 & 54.0 \\
\hline rented/other & 24,121 & 46.0 \\
\hline \multicolumn{3}{|l|}{ Type of dwelling } \\
\hline flat/shared & 17,172 & 32.8 \\
\hline single-family dwelling & 35,231 & 67.2 \\
\hline \multicolumn{3}{|l|}{ Satisfaction with dwelling } \\
\hline unsatisfied or neutral & 6,094 & 11.6 \\
\hline satisfied & 46,309 & 88.4 \\
\hline \multicolumn{3}{|l|}{ Degree or urbanisation } \\
\hline weakly urbanised & 11,354 & 21.7 \\
\hline moderately urbanised & 13,249 & 25.3 \\
\hline urbanised & 15,654 & 29.9 \\
\hline strongly urbanised & 12,146 & 23.2 \\
\hline \multicolumn{3}{|l|}{ Change in socio-economic status score of neighbourhood 1998-2002 } \\
\hline decrease & 19,731 & 37.7 \\
\hline stable & 22,982 & 43.9 \\
\hline increase & 9,690 & 18.5 \\
\hline \multicolumn{3}{|l|}{ Personal opinion about neighbourhood change over last year } \\
\hline neighbourhood deteriorated & 8,335 & 15.9 \\
\hline neighbourhood stayed the same & 33,645 & 64.2 \\
\hline neighbourhood improved & 10,423 & 19.9 \\
\hline \multicolumn{3}{|l|}{ Percentage of neighbourhood population subject to urban renewal in 1998} \\
\hline$<10$ & 43,086 & 82.2 \\
\hline $10-50$ & 6,842 & 13.1 \\
\hline$>50$ & 2,475 & 4.7 \\
\hline
\end{tabular}


TABLE 2. Multilevel logistic regression of the wish to leave the neighbourhood $(N=52,403)$

\begin{tabular}{|c|c|c|c|c|c|c|c|c|c|c|c|c|c|c|}
\hline \multirow{2}{*}{\multicolumn{3}{|c|}{ Model 0}} & \multicolumn{3}{|c|}{ Model 1} & \multicolumn{3}{|c|}{ Model 2} & \multicolumn{3}{|c|}{ Model 3} & \multicolumn{3}{|c|}{ Model 4} \\
\hline & & $* * *$ & -0.285 & 0.065 & $* * *$ & -0.480 & 0.067 & $* * *$ & -0.217 & 0.067 & $* * \star$ & -0.420 & 0.069 & $* \star \star *$ \\
\hline Age & & & -0.051 & 0.005 & $* * *$ & -0.057 & 0.005 & $* * *$ & -0.051 & 0.005 & $* * *$ & -0.056 & 0.005 & $* * *$ \\
\hline \multicolumn{14}{|l|}{ Household type (ref = single) } & $* * *$ \\
\hline couple, no kids & & & 0.159 & 0.035 & $* * *$ & 0.131 & 0.035 & $* * *$ & 0.160 & 0.035 & $* * *$ & 0.131 & 0.035 & $* * *$ \\
\hline couple with kids & & & 0.027 & 0.039 & & -0.008 & 0.039 & & 0.029 & 0.039 & & -0.006 & 0.039 & \\
\hline lone parent hh & & & 0.212 & 0.053 & $* * *$ & 0.183 & 0.053 & $* * *$ & 0.210 & 0.053 & $\star \star \star *$ & 0.181 & 0.053 & $\star \star * \star$ \\
\hline other hh & & & 0.202 & 0.070 & $* * *$ & 0.192 & 0.070 & $* * *$ & 0.206 & 0.070 & $* * *$ & 0.194 & 0.070 & $* * *$ \\
\hline Income & & & 0.012 & 0.008 & & 0.016 & 0.008 & ** & 0.012 & 0.008 & & 0.017 & 0.008 & $* *$ \\
\hline \multicolumn{15}{|l|}{ Level of education (ref $=$ low) } \\
\hline middle education & & & 0.109 & 0.031 & $* * *$ & 0.135 & 0.032 & $* * *$ & 0.110 & 0.032 & $* * *$ & 0.134 & 0.032 & $* * *$ \\
\hline high education & & & 0.249 & 0.037 & $* * *$ & 0.299 & 0.037 & $* * *$ & 0.258 & 0.037 & $* * *$ & 0.302 & 0.037 & $* * *$ \\
\hline Ethnic minority (cf. no ethnic minority) & & & -0.069 & 0.047 & & -0.006 & 0.048 & & -0.080 & 0.047 & * & -0.013 & 0.048 & \\
\hline Recent mover status (cf = no) & & & -0.378 & 0.037 & *** & -0.323 & 0.037 & *** & -0.386 & 0.037 & *** & -0.328 & 0.037 & *** \\
\hline Rental dwelling (cf. owner-occupied dwelling) & & & 0.339 & 0.031 & $* * *$ & 0.276 & 0.031 & $* * *$ & 0.345 & 0.031 & $* * *$ & 0.279 & 0.031 & *** \\
\hline Single-family dwelling (cf. flat/apartment) & & & -0.412 & 0.033 & *** & -0.418 & 0.033 & *** & -0.414 & 0.033 & $* * *$ & -0.417 & 0.033 & $* * *$ \\
\hline Satisfied with dwelling (cf. unsatisfied) & & & -1.576 & 0.032 & *** & -1.484 & 0.033 & *** & -1.595 & 0.032 & *** & -1.486 & 0.033 & *** \\
\hline \multicolumn{15}{|l|}{ Degree of urbanisation (ref = weakly urbanised) } \\
\hline moderately urbanised & & & 0.144 & 0.044 & $* * *$ & 0.129 & 0.044 & *** & 0.112 & 0.044 & $* * *$ & 0.102 & 0.044 & ** \\
\hline strongly urbanised & & & 0.188 & 0.045 & $* * *$ & 0.155 & 0.045 & $* * *$ & 0.128 & 0.047 & $* * *$ & 0.105 & 0.047 & $* *$ \\
\hline very strongly urbanised & & & -0.004 & 0.060 & & -0.040 & 0.059 & & -0.018 & 0.064 & & -0.048 & 0.064 & \\
\hline Status score 2002 & & & -0.076 & 0.021 & $* * *$ & -0.073 & 0.021 & $* * *$ & -0.063 & 0.023 & $* * *$ & -0.059 & 0.023 & $* * *$ \\
\hline \% Ethnic minorities 2002 & & & 0.018 & 0.002 & $* * *$ & 0.015 & 0.002 & $* * *$ & 0.014 & 0.002 & $* * *$ & 0.012 & 0.002 & $* * *$ \\
\hline \% Rented dwellings 2002 & & & -0.002 & 0.002 & & -0.003 & 0.002 & & -0.002 & 0.002 & & -0.003 & 0.002 & \\
\hline Interaction own ethnicity * \% ethnic minorities & & & -0.013 & 0.002 & $* * *$ & -0.012 & 0.002 & $* * *$ & -0.012 & 0.002 & $* * *$ & -0.011 & 0.002 & *** \\
\hline Interaction own tenure (renting) $* \%$ rented dw & ellings & & -0.004 & 0.001 & *** & -0.005 & 0.001 & *** & -0.004 & 0.001 & $\star \star *$ & -0.004 & 0.001 & $\star \star *$ \\
\hline \multicolumn{15}{|c|}{ Opinion about development neighbourhood in the last year (ref = no change) } \\
\hline 'neighbourhood deteriorated' & & & & & & 0.847 & 0.031 & *** & & & & 0.839 & 0.031 & *** \\
\hline 'neighbourhood improved' & & & & & & -0.038 & 0.032 & & & & & -0.034 & 0.032 & \\
\hline \multicolumn{15}{|c|}{ Socio-economic status change $1998-2002$ (ref = no change) } \\
\hline decrease & & & & & & & & & -0.012 & 0.031 & & -0.009 & 0.031 & \\
\hline increase & & & & & & & & & -0.066 & 0.039 & * & -0.053 & 0.039 & \\
\hline Percentage-point increase in non-western ethn & ic minor & ities & -2002 & & & & & & 0.020 & 0.006 & $* * *$ & 0.011 & 0.007 & \\
\hline Percentage households moved in 2002 & & & & & & & & & 0.025 & 0.005 & *** & 0.022 & 0.005 & *** \\
\hline \multicolumn{15}{|c|}{ Proportion inhabitants subject to urban renewal in 1998 (ref $=0-10 \%$ ) } \\
\hline $10-50 \%$ subject to urban renewal & & & & & & & & & -0.090 & 0.048 & * & -0.094 & 0.048 & * \\
\hline over $50 \%$ subject to urban renewal & & & & & & & & & -0.367 & 0.073 & $\star * *$ & -0.316 & 0.073 & $\star \star \star *$ \\
\hline $\begin{array}{l}\text { U0j } \\
\text { Wald (df) }\end{array}$ & 0.017 & $* * *$ & $\begin{array}{r}0.062 \\
568 \varepsilon \\
\end{array}$ & $\begin{array}{r}0.010 \\
37(22) \\
\end{array}$ & $\star \star \star *$ & $\begin{array}{r}0.056 \\
616 \\
\end{array}$ & $\begin{array}{r}0.010 \\
0(24) \\
\end{array}$ & $* \star * *$ & $\begin{array}{r}0.050 \\
583 \\
\end{array}$ & $\begin{array}{r}0.010 \\
23(28) \\
\end{array}$ & $\star * *$ & $\begin{array}{r}0.048 \\
6225 \\
\end{array}$ & $\begin{array}{r}0.010 \\
44(30) \\
\end{array}$ & $* \star *$ \\
\hline
\end{tabular}

Wald (df)
$*=\mathrm{p}<0.10 ; * *=\mathrm{p}<0.05 ; * * *=\mathrm{p}<0.01$ $\begin{array}{rr}0.062 & 0.010 \\ 5688,87 & (22)\end{array}$ $6168,00(24)$ $5838,23(28)$ $6225,44(30)$ 